\title{
The Function Analysis and Skill Teaching of Badminton In College Physical Education
}

\author{
Qiang Wu \\ School of Changchun University of science and technology, Changchun, Jilin 130000, China. \\ 26976698@qq.com
}

Keywords: badminton, origin, application, skill teaching, teaching significance.

\begin{abstract}
College students should not only learn professional knowledge, but also should actively improve their physical quality, and then promote the progress of all aspects of the comprehensive development of a comprehensive talent. In all kinds of sports, badminton has a unique role and significance. Badminton can increase energy consumption, promote fat decomposition, reduce its synthesis, but also can reduce body fat and improve the composition of the body composition. Therefore, badminton is the best choice for leisure, entertainment and fitness.
\end{abstract}

\section{Introduction}

Badminton is not only an important sport event, but also a favorite body-building sport for the masses. It is suitable for both the old and the young, can amuse oneself, fully exercise, strengthen the physic fitness, cultivate indomitable will and good morals, and its graceful form of motion has ornamental value.

\section{The Origin and Development of Badminton}

It is said badminton was first appeared in the 14-15 century in Japan, and bats were made of wood. The ball was made of cherry kernels and inserted into feathers. The ball was made of cherry kernels that inserted with feathers. The ball was so heavy that flied fast because the ball support was like a cherry stone, the feathers were easily damaged, and the cost of the ball was too high. So the sport was popular just a period of time then disappeared gradually. Until about eighteenth Century, India, Pune had a very similar badminton game with the early Japanese, the ball was made by round cardboard about $6 \mathrm{~cm}$ in diameter that was inserted into a shuttlecock in the middle (similar to China's shuttlecock), the board is made of wood, the game was played by two people standing opposite each other with holding a wooden board to return the ball. Modern badminton was born in England, about 1800 years, it was derived from tennis. We can notice that today's badminton courts are still very similar with tennis courts. In 1870, there were appearing balls made of feathers, cork, and rackets with string. In 1873, British Duke of Bao Fute had a badminton game show in the Bloomington manor of Glasgow County. Since then, badminton has developed gradually, "Bloomington" which became the name of the badminton, written in English is "Badminton". At that time the venue is a gourd shaped, both sides are wide and narrow at the center, narrow at the hanging net, it was converted to rectangular until 1901. Modern badminton first appeared in the mid nineteenth century, it comes from the development and evolution of the movement that called "shuttlecock Cricket" (battledore and shuttlecock). The origin of the "shuttlecock Cricket" could be traced back to ancient Greece, China, Japan and India. Today, badminton is especially popular in Asia and Europe. It has become an official event in the 1992 Olympics.

In 1948, the first competition was held once every 3 years there were 5 singles and 4 doubles in each game, 9 matches in total, and the competition was completed in two days. In 1984, the holding of the competition was changed into an even number of years, and the 5 match system instead of 9 match system, which were 3 singles and 2 doubles. In1956, the trophy cup, which was donated by the world 
famous badminton player Betty Uber as the mobile trophy of the world badminton women's team competition. It held the first Uber Cup in 1956, each game consists of 3 singles, 4 doubles, a total of 7 games. In 1984, the match was changed that it was held with the Thomas cup at the same time, and adopting the same 5 game system. In 1977, the first World Badminton Championships were held in Malmo, Sweden, where 5 individual events were held, it was originally held in odd numbered years, which is now being held once a year. In 1989, the first Sudirman Cup competition was held in Indonesia. Indonesia donated a trophy named after the Indonesian Sideman to the International Badminton Federation as the mobile trophy of world badminton mixed male and female team event. The Sudirman Cup match was composed of 5 games including men' and women' singles, men' and women' doubles and mixed doubles. The International Badminton Federation officially changed its name to the Badminton World Federation in 2006, for short, BWF.

\section{Analysis of the Significance of Applying Badminton to Physical Education in Universities}

\subsection{Badminton used in college sports helps to improve students' physique and helps students.}

Shape healthy body shape.

Badminton is a kind of indoor movement which has net, which is not only a reflection of individual play, but also a display of doubles coordination. In less than 80 square meters of space, through underhand, overhand, moving left and right, front court and back court' hitting, the fight against the opponent with spirit of fighting bravely is the full display of the physical integrity and quality of people's intelligence, agility, wit, toughness, patience, coordination and so on. Badminton is a kind of civilized sport that can last for long time. Indoor mesh movement whose net height is close to the height of the human body is the most civilized movement for human beings. The fast moving front, back, midfielder jump smash, midfielder ball, the step, rubbing, hanging hook, push, flutter and doubles in front of the net require the hitter to have good strength, speed, agility, flexibility, intelligence and other quality. The process of mastering and being familiar with a variety of techniques is the process of improving physical fitness, improve the activities of muscles and joints of various parts, make the nervous system be regulated and the functions of the respiratory and circulatory systems be improved, improve aerobic and anaerobic metabolism, activate the beneficial cells of the body and enhance the overall physique. in badminton sport, through the racket waving hitting a certain height of the net, hitting more round ball placement and controlling efforts and speed, people fully demonstrate the hitter who is flexible and witty, handsome and arouse the interest of badminton. They cooperate with each other and encourage each other in doubles, so as to achieve a noble state. In short, people use a variety of wonderful body language, freely to sprinkle themselves and express themselves, so as to achieve the goal of self-entertainment.

\subsection{Badminton used in college sports can help students form a healthy and upward mental state.}

In badminton, especially in the match, in the case of close competition, the process which athletes consume a lot of energy is also the process of training the quality of will. When the physique appears "extreme pole" phenomenon, whose will is strong, who can win the final victory the cultivation of this indomitable will helps to improve the courage to overcome difficulties. Through the offensive and defensive control and anti-control, people not only need to fight, but also need the battle of wits, it is also a kind of exercise and test for personal psychological quality. While giving full play to the technical level, but also to strengthen thinking ability, try to figure out others' tactical intent and choose appropriate strategies to seize the aircraft showdown. Through intense competition, people think more quickly and improve their enterprising spirit and psychological quality. 


\section{Methods and Measures of Badminton Used in Sports}

\subsection{Basic Theory Knowledge of Badminton.}

Based on the combination of the latest development trend of badminton and basic theory knowledge teaching,badminton technique and tactics teaching method of innovation and innovation training, quality training of badminton and badminton basic technical skills and tactics of in-depth research and analysis, from theory to practice, from easy to difficult, from the shallower to the deeper to analyze the technology and tactics of teaching and training and practical aspects. The book integrates the latest development of badminton, research results and teaching experience, with the features of rich content, clear language, clear structure and illustrations, fully embodies the advantages of its fitness, practicability and guidance etc.

\subsection{The Role of Badminton Teaching Methods in Practice.}

Badminton, as a kind of ball games, has many fans in our country, and it is also an important content of Campus Physical Education. Badminton is a sport with high technical requirements. Therefore, it is necessary to cultivate students' interest in learning and build-up confidence in study. To effectively improve the teaching quality of badminton, achieve the purpose of improving the physical quality of students, and lay a solid foundation for the future development of students, in teaching practice, teaching methods must be a reasonable choice of badminton, in order to comprehensively improve the teaching quality of badminton.

\section{The Basic Skills of Badminton Teaching}

There are many techniques in badminton. In college physical education, more exercises are made for students' basic skills, which mainly include three aspects: grip position, service position and pace of movement.

\subsection{Basic Grip Position of Badminton.}

The grip position is the most basic skill in badminton, and it is also the premise of correct badminton movement. The most basic grip methods are forehand grip and backhand grip, with the right hand grip as an example. Forehand grip: A forehand grip is applied to the ball from the right side of the body to the top of the head. The tiger's eye is on the side of the upper side of the handle, the little finger, ring finger and middle finger are held together, the index finger is slightly apart, and the thumb is close to the middle finger. Backhand grip: The ball from the left side of the body, the athletes should first turn (back to net) and then stroke, backhand grip, that is, on the basis of forehand grip, the thumb and forefinger will handle slightly outward, thumb affixed to the top on the handle inside the wide face.

\subsection{Serving and Receiving of Badminton.}

Serve: the methods of serve have forehand serve and backhand serve, according to the arc of the ball in the air, serve can be divided into high clear, flat golf, and flick service, net ball and floating angled drops. Receiving: If the serve is good, it is the beginning of the victory, then the best of receiving is the first step to victory. The server will throw the receiver into confusion by using changeable serve and seize the initiative, while the receiver disturb the intention of server by using changeable receiving.

\section{References}

[1]. Tao Shuai, Investigation and Research on junior high school badminton movement in Changchun [D]. Jilin Institute of physical Education, (2016).

[2]. Lei Junlin, Study on the development pattern and situation of badminton in Colleges and universities in China [D]. Hunan Normal University, (2014).

[3]. Wang Chao, Study on the current situation and Countermeasures of badminton development in Colleges and universities in Qingdao [D]. Chinese Marine University, (2014). 
[4]. Chai Chengjun. Study on Badminton Teaching in some colleges and universities in Shanghai [D]. Shanghai University of Sport, (2014).

[5]. Yu Wentao, Experimental study on optimizing teaching methods of badminton basic skills [D]. Beijing Sport University, (2013).

[6]. Gao Yan, Study on the current situation and Countermeasures of public sports badminton optional course in Colleges and universities in Zhengzhou [D]. Henan Normal University,(2013). 